\title{
Heine y Santayana ante la primera filosofía alemana
}

\author{
Heine's and Santayana's Readings of Early German Philosophy
}

DANIEL MORENO MORENO*

\begin{abstract}
Resumen: Merece la pena contrastar la interpretación que de la primera filosofía alemana hicieron, con ochenta años de diferencia, Harry/ Heinrich Heine y Jorge/George Santayana. Poetas ambos, y buenos prosistas, comparten, entre otros rasgos, un estilo de alta divulgación filosófica. En Heine aparecen muchos de los ahora tópicos en loor de la filosofía alemana en comparación con la no-filosofía francesa; Santayana adopta una postura más distanciada respecto al pensamiento alemán, demasiado fundido, a su juicio, con la religión. Heine acepta la identidad entre lo ideal y lo real, Santayana, por el contrario, llama a esa identificación egotismo.

Palabras clave: idealismo, materialismo, deísmo, panteísmo, egotismo.
\end{abstract}

\begin{abstract}
This paper deals with two contrasting readings of early German philosophy, those of Harry/Heinrich Heine and of Jorge/George Santayana; their contribution were separated by eighty years. Both were poets and fine prose writers, both cultivated high philosophical popularizing, but in fact from a very different point of view. Heine tends to praise early German philosophy, primarily in opposition to French thought. Whereas Santayana tends to separates himself from German philosophy on the whole, too joint, in his opinion, to religion. Heine understands it as identifying the ideal as the rational. Santayana, on the other hand, qualifies its identity as egotism. Keywords: Idealism, Materialism, Deism, Pantheism, Egotism.
\end{abstract}

La casualidad ha hecho que casi coincidan en las librerías dos rescates recientes que, desde ángulos distintos, invitan a una nueva reflexión sobre el origen de la filosofía alemana en el contexto del nacimiento de la nación moderna. Me refiero a El egotismo en la filosofía alemana (1916) de George Santayana, publicado por Biblioteca Nueva en 2014, y a Sobre la historia de la religión y la filosofía en Alemania (1835) de Heinrich Heine, preparado por el profesor Manuel Garrido -utilizando para ello la edición de Manuel Sacristán de

Recibido: 10/11/2015. Aceptado: 15/12/2015.

* Profesor del Departamento de Filosofía del IES Miguel Servet, Zaragoza. E-mail: dmoreno@unizar.es. Ha traducido varios libros y doce ensayos de Santayana. Ha publicado más de treinta artículos y ponencias en español e inglés sobre Santayana y sobre Miguel Servet. Es autor de Santayana filósofo. La filosofía como forma de vida (Trotta, 2007), recientemente traducido al inglés por Charles Padrón para Bucknell University Press. Sobre Servet ha publicado Miguel Servet teólogo iluminado. ¿Ortodoxia o herejía?, (Institución «Fernando el Católico», 2011). 
1967- para su colección Los esenciales de la filosofía, en 2015, y que ha resultado ser, tras su fallecimiento en enero de 2015, el último volumen de la colección publicado a su cargo.

Que la historia, en general, y la historia de la filosofía, en particular, presenta algo más que una mera sucesión cronológica y contingente de hechos seguramente es una decisión -de marchamo hegeliano- cuestionable pero de algún modo inevitable porque ¿quién es capaz de vivir/pensar desde la multiplicidad? Se impone, entonces, la interpretación, lo que convierte a la historia en un campo de batalla ideológico. También en el caso de la filosofía. Sólo por hablar de historia se sitúa uno por encima de los meros anales, de igual modo que sólo por hablar de filosofía ya se reconoce cierta disciplina, por más que, desde su mismo nacimiento en los albores del siglo diecinueve, vaya acompañada por la neurótica cuestión de la propia identidad. Una buena ilustración de este hecho la aporta la comparación entre las distintas interpretaciones que de la primerísima filosofía alemana hacen Heine y Santayana. Creo que es interesante dar simplemente a conocer la opinión de estos dos poetas-filósofos, darles visibilidad, contraponerlos y dejar que las conclusiones salgan por sí solas. Son escritos llenos de sugerencias, dado que su punto de vista es característico, nada académico, nada de repeticiones vacías. De ese modo enlazan con la concepción del «filósofo mundano» que volvió a la vida en el Renacimiento y que tuvo su esplendor en la Ilustración, antes de refugiarse de nuevo en la Universidad, donde se encontró con los restos aún calientes de la escolástica. Suponen ambos pensadores un soplo fresco, animan a escribir filosofía sin la seriedad de la erudición ni de las complejas notas al pie, sino a vuela pluma, corriendo a veces el riesgo de la trivialidad, incluso de la demagogia, pero provocando por ello en el lector el saludable efecto de descubrir el placer de pensar por uno mismo. Nunca empujados por la ignorancia, claro, sino por la seguridad de haber entendido, de haber sabido leer; algo que, de forma natural, anima a coger la pluma, muy lejos de la seriedad, de la exigencia de cumplir innumerables requisitos antes de tener la opción de «sentar cátedra».

\section{Heine y Santayana bifrontes}

Heine, nacido en 1797 en la confluencia del pequeño río Düssel con el gran Rin, llamado la primera parte de su vida Harry -a la inglesa, puesto que sus padres, judíos ilustrados, admiraban Inglaterra- y la segunda, al bautizarse como cristiano protestante, Heinrich, su nombre germanizado, fue un estupendo intérprete entre dos naciones llamadas a mantener una relación difícil. Francia, tras su revolución y las luchas napoleónicas, ya estaba en construcción, alternando entre república y monarquía, y con París siempre a la cabeza; mientras tanto, Alemania sólo nombraba en ese momento una comunidad idiomática que flotaba por encima de múltiples unidades políticas, diversas tradiciones culturales y dos religiones dominantes, la protestante y la católica. La patria de Heine, Renania, cumplió el papel de vía de comunicación tanto de los ejércitos tanto como de las diversas influencias culturales, y la misma vida y obra de Heine urdieron tal urdimbre entre las dos orillas del Rin que el famoso poeta romántico bien merece el título de Hermes reencarnado. Él fue muy consciente de las dos Francias que luchaban entre sí, así como de las dos Alemanias también en guerra civil; de modo que da que pensar el hecho de que, si hubiera sido tan longevo como su odiadoadmirado Goethe, habría asistido a la guerra franco-prusiana de 1870. 
A los 34 años de edad, Heine cruza en Rin animado por la revolución francesa de julio de 1830 . Atrás quedaban sus ya famosos poemas -el internacionalmente conocido Buch der Lieder (Libro de canciones) (1827), en realidad una edición conjunta de sus libros anteriores, inspiradora de tantos músicos-, su empresa Harry \& Co., su primer amor, su relación con August Schlegel en la Universidad de Bonn, su contacto con Goethe en Weimar, su asistencia a las clases de Hegel en Berlín, algunas «capitulaciones» (Sacristán, 1964, 19) -así llama Sacristán al seguramente forzado bautismo de Heine para hacerse protestante y evitar su marginación como judío- y sus fallidos intentos de ser profesor, funcionario o periodista. Heine iba camino de París al calor de su admirada revolución, la de 1830, que había derrocado al rey por derecho divino, Carlos X, y puesto en su lugar al rey por gracia de la burguesía, Luis Felipe de Orleans. Este compromiso con la revolución fue vivido y presentado por Heine como el triunfo de lo político sobre lo poético y es el contexto en el que ve la luz Zur Geschichte der Religion und Philosophie in Deutchland (Sobre la historia de la religión y la filosofía en Alemania). Pero las crónicas que Heine publica en el Allgemeine Zeitung (Ausburg) acaban molestando dado que, en su genérica defensa de la libertad, no solo muestra su odio a los nobles y al clero, sino también, y de forma más intensa aún, a burgueses, banqueros y empresarios; da, además, la bienvenida al emergente socialismo, a la vez que se presenta como moderado y monárquico. Finalmente, la Gaceta General de Ausburgo lo despide. Con todo, el año de su crack total fue 1848: a la nueva revolución -que, esta ya sí, le asusta- se suma su quiebra financiera personal, el conocimiento público de que recibía dinero de Francia y la explosión de su larvada enfermedad, que le obliga a vivir en cama hasta el final de sus días, en 1856.

A juicio del profesor Sacristán, el derrumbe final no se debió a causas externas sino a causas internas, casi constitutivas: «Lo que Heine consideró su doctrina en la época floreciente de su vida era un conjunto de inseguras vaguedades, hemiconceptos y gestos de idea, meros ecos de estados de ánimo. En eso no puede asentarse firmemente ninguna consciencia, por aguda que sea. El secreto de las desaventuras de la consciencia de Heine está precisamente ahí (...). La enfermedad, la ruina y el miedo triunfaron porque no tenían enfrente más que una frágil choza ideológica en la que nunca habitó segura la consciencia de Heine» (Sacristán, 1964, 48). Así, por el contrario, lo describe un alma más afín, Max Aub, desde México en 1956: «En su obra hay para todos los gustos, para todas las edades; para el radical y el conservador -si es persona de gusto, cosa que a veces sucede-, para el amante y el amado, el escéptico y el creyente, el vigoroso y el enfermo, el optimista y el que no lo es, para el amante de la paz y el creyente en los bienes de la guerra, el sencillo y el que dejó de serlo, para el romántico o quien prefiere los clásicos, para el inteligente y para el cerrado, para el político y para el que no quiere hablar de esa panacea, siempre en ciernes. Todo dicho con tanta gracia, desparpajo, amor o desprecio que, en todo momento ensancha el alma» (Aub, 2000, 75).

Santayana, por su parte, nació en Madrid en 1863. A los cinco años su madre regresa a Boston con los hijos de su primer matrimonio, a donde viaja también Santayana con su padre cuatro años más tarde para recibir educación norteamericana. De esta manera se encuentra en Boston con nueve años al comienzo de la que será una brillante carrera que le llevará a Harvard y a ser considerado en la actualidad un filósofo clásico americano. Aunque tampoco rompe los lazos que le unen a España, no reconociéndose ni totalmente bostoniano ni 
totalmente español, escribiendo en inglés pero sintiendo afinidades naturales con tradiciones no anglonorteamericanas. A su familia debe también su particular educación religiosa, formalmente católica, pero de contenido deísta, por influencia de sus padres, y devotamente creyente por influencia de su hermanastra Susana, a la que Santayana estuvo siempre muy unido. De sus padres acepta que la religión no es más que el producto de la imaginación humana, pero siente una atracción instintiva por la deliciosa épica católica. Sus numerosos viajes cruzando el Atlántico, sus estancias en Londres, Paris y Madrid, y sus fuertes vínculos con Ávila -sin olvidar que sus últimos veintisiete años los pasó en Roma- dotaron no sólo a su vida sino también a su obra, de un característico aspecto híbrido, donde se encuentran y mezclan, como adelanto de un modo de estar cada vez más extendido y habitual, polifacéticos elementos en principio dispares. Santayana puso así en contacto ambas orillas del Atlántico y estableció un fructífero diálogo entre las culturas europeas -la antigüedad, la tradición y el clasicismo- y norteamericana -el pragmatismo y la modernidad-. Su voz sonó con fuerza en el Harvard de sus años de poeta y profesor hasta que, en 1912, decidió abandonar su puesto académico e instalarse en Europa, para no volver más a Estados Unidos; no obstante, alcanzó renombre internacional en los difíciles años de la Segunda Guerra Mundial, aunque le rodeó un discreto silencio en los años posteriores a su muerte, en 1952.

De ahí que Savater escribiera, allá por el año 1985, que Santayana «se supo a la vez próximo y errante, huérfano y heredero. Vivió de un peculiar modo desvaído, como si no fuera del todo de ninguna parte, y los hombres que le vieron pasar entre ellos con sobrio y ceremonioso distanciamiento nunca le tuvieron por uno de los suyos» (Savater, 2012, 65). El profesor Beltrán, por su parte, considera que «la novedad y el valor de la obra de Santayana no consisten sólo en apropiarse metafórica o simbólicamente de una serie de rasgos como el de viaje, nomadismo, extranjería, para instrumentalizarlos e incorporarlos a su gramática filosófica, algo que resulta familiar en todas las bifurcaciones que recorre la historia de la filosofía, sino más bien y sobre todo en hacer de estos auténticos conceptos constitutivos, el nervio que alienta todo un programa de vida y de trabajo» (Beltrán, 2008, 52). Finalmente, en la presentación de El egotismo en la filosofía alemana se lee: «basta cotejar los datos aportados sobre su vida, obra y bibliografía para constatar la reciente eclosión de su figura, circunstancia que quizá le haga merecer el título de un clásico para el siglo XXI. (...) Se puede decir que Santayana ha sobrevivido a la quiebra tanto de los modelos teóricos basados en los «grandes relatos» dominantes durante buena parte del siglo XX como de los planteamientos postmodernos de los últimos decenios» (Moreno, 2014, 15).

A la altura de 1916, cuando Santayana publica Egotism in German Philosophy, ya tiene a sus espaldas una extensa obra, entre la que destacan Sonetos y otros versos (1894), El sentido de la belleza (1896), Lucifer. Una tragedia teológica (1899), Interpretaciones de poesía y religión (1900) y su famosa pentalogía, libro de referencia del naturalismo, La vida de la razón (1905-6). Escrito con un estilo de alta divulgación y dirigido a un público ávido de estar a la última, la inmensa minoría de la que habló Juan Ramón, no ha de extrañar el rápido éxito de El egotismo en la filosofía alemana. Éxito al que no fue ajeno su fecha de edición: cuando Europa estaba inmersa en la Gran Guerra ${ }^{1}$, uno de cuyos contendientes, Alemania,

1 Santayana, como Heine, también vivió su particular revolución; aunque, en lugar de ser una guerra civil, fue la conjunción de varias guerras civiles volcadas hacia afuera bajo la forma de enfrentamientos entre naciones. Me 
era criticado en el libro y precisamente desde la filosofía. Fueron momentos propicios para múltiples libros de guerra, compañeros de viaje efectivos del libro de Santayana, aunque es difícil encontrar en él, como en el resto de la obra santayaniana, juicios sumarios -no digamos ya sumarísimos- sobre ningún autor. Santayana entra en cada uno de ellos, comprende sin dejarse cautivar, y sale.

Heine y Santayana comparten, como se ve, numerosos rasgos, que destacan sobre sus obvias diferencias. Ambos recibieron en la cuna una educación ya avanzada tanto en lo cultural como especialmente en lo religioso. Ambos utilizaron dos nombres -Harry y Heinrich, Jorge y George-, algo que podría ser meramente anecdótico si no fuera porque en los dos casos adquiere carácter simbólico. Se puede decir también que ambos, en su vida y en su obra, adoptan un talante fronterizo: entre Alemania y Francia en el primer caso, y entre Estados Unidos y Europa en el caso de Santayana. Los dos, a mitad de su vida, toman la decisión -prácticamente forzada en el caso de Heine y largamente meditada en el caso de Santayana- de cambiar de residencia, desde el lugar de su formación hacia su lugar de elección, sin por ello dejar de mirar a los dos lados. Su tarea de fondo fue la de ser intérpretes, la de servir como traductores entre mundos culturales que, precisamente, empezaban a alejarse entre sí en ese momento, dejando atrás la previa cultura ilustrada común entre Francia y Alemania en el caso de Heine y manifestando Estados Unidos rasgos culturales idiosincráticos autónomos respecto a Europa en el caso de Santayana. Así, del mismo modo que Heine explica la religión, la filosofía y la cultura alemanas a los franceses en Sobre la historia de la religión y la filosofía en Alemania y en La escuela romántica, Santayana, en Carácter y opinión en Estados Unidos, hace lo propio con la nueva cultura norteamericana respecto a Inglaterra. Los dos, en definitiva, fueron poetas y prosistas, prosistas y poetas, por más que Heine sea un poeta romántico y Santayana aspire a ser un poeta posromántico.

\section{Heine sobre la filosofía alemana}

Sobre la historia de la religión y la filosofía en Alemania es presentada así por Juan Carlos Velasco: «El texto está compuesto de un modo vivo, con su peculiar estilo irónico y polémico, lleno de sarcasmos, pullas chispeantes y digresiones tan sólo aparentes, pues se trata de uno de los escritos de Heine con una mayor trabazón interna, para cuya elaboración se documentó concienzudamente, pese a que nunca dejó de burlarse de la pedantería que conllevan los alardes de erudición. Es consciente de que si, por casualidad, los filósofos profesionales echaran un vistazo a su libro, no lo mantendrían por largo rato en sus manos dada la escasa categoría de lo expuesto en él» (Velasco, 2008, 26).

refiero naturalmente a la Primera Guerra Mundial. La actitud de Santayana puede sintetizarse así: «El mismo mes en que se sucedieron las declaraciones de guerra, escribe a su hermana Susana mostrando una mezcla de excitación y de calma, al comprobar lo humana que es la sinrazón. Sus simpatías están con Francia, Bélgica y Gran Bretaña, aunque no siente rabia ante las incursiones alemanas porque ve en ellas la encarnación de su determinación heroica de convertirse en los dueños de Europa. (...) Su estado de ánimo, por otro lado, es de abatimiento y resignación. Se dedica a leer a Dickens y libros sobre los alemanes y a escribir prolíficamente» (Moreno, 2007, 146-147). 
El marco general en el que se inscribe la interpretación heiniana de la filosofía alemana presenta cuatro rasgos característicos. El primero viene reflejado en el título, exactamente en la y que une religión y filosofía. Es un detalle de suma importancia dado que Heine considera que la filosofía en Francia, el materialismo, ha roto esa hilaza, de modo que no sólo ha dejado de estar supeditada a la religión sino que, al no admitir tampoco regir la cultura al lado de la religión, aspira a gobernar en solitario. Cuando, a su juicio, la cuestión filosófica por excelencia sería la elucidación de la naturaleza de Dios. En este sentido, Heine piensa que lo que se hace en Francia ya no es propiamente filosofía y que esta se refugia en Alemania, dado que identifica la filosofía con la concepción de la naturaleza animada por ideas, mientras que la concepción de la naturaleza mecanicista propia de la física cartesiana le parece muerta ${ }^{2}$. El segundo rasgo es la importancia que le concede al estilo: así destaca en cada autor si su estilo es matemático o dialéctico, claro u oscuro, y, en especial, en qué idioma está escrito. Con un claro tono polémico, Heine escribe que «la gran Francia, la tierra ruidosa, movida y charlatana de los franceses, no fue jamás un suelo adecuado para la filosofía; ésta no fructificará nunca en él»3 (Heine, 2015, 78), y que «el alemán no sólo es adecuado para las investigaciones metafísicas, sino que lo es mucho más que el latín. (...) En ninguna otra lengua habría podido revelar la naturaleza su obra más secreta como lo hizo en nuestra querida lengua alemana» (Heine, 2015, 96). La tercera característica consiste en el punto de vista que adopta, esto es, la filosofía desde la que escribe; a mi juicio, su filósofo de referencia no es, tal como establece Félix Duque, Hegel, sino el primer Schelling, junto al saint-simonismo. Habría que recordar que Heine perteneció a la escuela romántica à la Schlegel, influida precisamente por Schelling -las duras invectivas que le dedica en La escuela romántica ${ }^{4}$ van dirigidas a la segunda época de Schelling- y que los elogios a Hegel han de quedar muy cualificados por dos hechos: Sobre la historia de la religión y la filosofía en Alemania acaba con grandes elogios a Hegel pero sin resumir su filosofía y en sus Confesiones Heine cuenta que apenas lo entendió, por lo que quemó el manuscrito sobre su pensamiento ${ }^{5}$. Finalmente, el cuarto rasgo consiste en pasar a primer plano el aspecto social, esto es, político, de la filosofía alemana, no destacado del todo en Alemania por «miedo a los resultados de su propio pensamiento, que no se atreven a comunicar al pueblo» (Heine, 2015, 78). Estos resultados

2 En este sentido, es muy ilustrativa, realmente de antología, la leyenda que Heine recoge al comienzo del libro tercero sobre el mecánico inglés que construyó un hombre sin alma. Lamentablemente a la edición de Garrido le faltan en ese importante paso ¡dos páginas! de la edición de Sacristán. En otros lugares, por cierto, hay también erratas repetidas y alguna frase que falta, indicio de una rápida o nula revisión de las pruebas. Por ello remito al lector a la estupenda edición de Juan Carlos Velasco -(Heine, 2008)-, que tiene en cuenta las últimas versiones críticas de la obra de Heine, especialmente la conocida como «la edición de Düsseldorf» (1973-1997), además de añadir a las notas de Sacristán, otras ricamente aclaratorias.

3 En el Apéndice que cierra La escuela romántica, dedicado a Victor Cousin, se puede leer: «he observado que a los franceses basta con decirles cuatro cosas de una doctrina (...) porque ellos saben combinar tan excelentemente ese poco en su espíritu y elaborarlo tan eficazmente que enseguida entienden la cosa mejor que nosotros mismos, y pueden así adoctrinarnos acerca de nuestro propio saber. Pienso muchas veces que las cabezas de los franceses son por dentro como sus cafés, llenos de espejos, de modo que cualquier idea que entre en sus cabezas se refleja en ellas miles de veces; con esa disposición óptica, hasta las cabezas más reducidas y estrechas parecen muy amplias y radiantes» (Heine, 2015, 303).

4 Cf. Heine, 2015, 237-244.

5 Cf. Heine, 1967, 1015-1022. 
serían nada menos que el anuncio de la futura -mejor, inmediata- revolución alemana, que estaría siendo preparada y precedida por las críticas al deísmo y por la expansión del panteísmo. Ese sería «el secreto a voces de Alemania» (Heine, 2015, 94).

Resulta conveniente en este punto tener en cuenta un texto ligeramente anterior, donde Heine expone su concepción de tal revolución. Se trata de «Introducción al escrito de "Kahldorf sobre la nobleza, en cartas al conde M. von Moltke"», de 1831, muy oportunamente añadido por Juan Carlos Velasco como apéndice a su edición de Sobre la historia de la religión y la filosofía en Alemania. En el contexto de las reacciones en Alemania a favor y en contra de la revolución francesa de 1830, el conde von Moltke escribió un panfleto a favor de los derechos de la nobleza, al que respondió el liberal Robert Wesselhöft, bajo el seudónimo de Kahldorf; Heine contribuye con un prólogo donde da a conocer dos ideas importantes: por un lado «la afinidad electiva» (Heine, 2008, 226) entre lo que los franceses hacen y lo que algunos alemanes piensan y sueñan, esto es, romper con lo existente y con la tradición -así Robespierre y Kant critican, Napoleón y Fichte imponen su Yo, la Restauración y Schelling vuelven a la tradición, y Luis Felipe de Orleans y Hegel son eclécticos ${ }^{6}-$; por otro lado, Heine explicita aquí, como en ningún otro escrito, qué tipo de revolución tiene en mente. Sus rasgos principales serían: la división de poderes establecida por Montesquieu, la crítica de la etiqueta cortesana llevada a cabo por Rousseau y del derecho divino del despotismo tan persistente en Voltaire, el establecimiento de una constitución libre, tal como Lafayette había hecho en las colonias inglesas en América, la lucha contra la minoría de edad cultural, contra el jesuitismo, y contra el oscurantismo de la Sorbona. Y los dos objetivos a conseguir serían acabar con la censura estableciendo la libertad de prensa - «clara luz del sol de la libertad de prensa» (Heine, 2008, 231) - y conseguir la igualdad civil. La libertad de prensa acaba con la demagogia y con la mentira, erradica la ignorancia y fomenta la inteligencia; finalmente, modera y humaniza al pueblo, tal como, apunta Heine, ha puesto de manifiesto la moderación de la revolución de 1830 respecto a la de 1789. Con todo, «la primera consigna de la revolución» (Heine, 2008, 233) consiste en acabar con los privilegios de la nobleza, con la aristocracia feudal, basada en la mera procreación, privilegios que Heine sufrió en sus carnes, precisamente por ser judío: derecho preferencial a puestos oficiales en la corte, las embajadas y el ejército, justicia preferencial, exoneración de cargas públicas, etc. Tamaña desigualdad civil, a su juicio, va en contra de la prosperidad general y enfrenta a la nobleza con el pueblo. Que este era el tema de la época lo ilustra la anécdota que cuenta Heine: ante la agresión que sufre un siervo por parte de un amigo suyo, que resulta ser conde, Heine reacciona empujando a su amigo y produciéndole una fractura en la pierna ${ }^{7}$. Esta era la revolución con la que Heine sueña para Alemania. Muy otra, entonces, de la que su compatriota

6 Tan repetido ha sido este paralelismo que resulta conveniente aclarar un posible malentendido. Como Heine, y tantos, consideran que las ideas mandan sobre la acción, si se contempla el paralelismo sub specie aeternitatis, puede parecer que los alemanes pensaron lo que llevaron a la práctica los franceses. Lo que Heine señala, sin embargo, es que lo que en Francia había sucedido era consecuencia de lo que los pensadores franceses habían pensado previamente; y lo que en Alemania se pensaba desde Kant sería el caldo de cultivo de la revolución alemana por venir, dado que los alemanes primero piensan y luego actúan.

7 Cf. Heine 2008 235. Es ilustrativo destacar que este mismo tema sobrevuela el Diario del viaje de un naturalista alrededor del mundo (1836), de Charles Darwin, donde siempre se sorprende, con dolor, del mal trato que los esclavos y los siervos sufren allá donde va. 
Marx atisbó en la revolución de 1848 y que tanto asustó a Heine. No se le puede culpar a Heine, entonces, de contradecirse en este punto, tal como hace George Lukács ${ }^{8}$, del mismo modo que, cuando en su obra se habla de revolución y de libertad, no se ha de entender por ellas ni las revoluciones ni las libertades del siglo veinte.

La tesis que defiende Heine es coherente con la unión que establece entre filosofía y religión: el cristianismo se convierte en catolicismo, este en protestantismo y este ha dado lugar a la filosofía alemana. Por el camino, da cumplida cuenta de las polémicas en Alemania ante la recepción de la ilustración, de Spinoza, de Kant y del ateísmo. A su juicio, las críticas de Voltaire a la religión sólo afectan al aspecto externo del cristianismo, no a su esencia, del mismo modo que la historia de la Iglesia sólo muestra su relación con el poder, no su impulso íntimo. Este consiste en la lucha del espíritu contra el cuerpo, esto es, contra la sensualidad y el goce, y en la defensa del conformismo. A pesar de que a Heine le entusiasma la poesía del espiritualismo, él prefiere una religión de la alegría, de la belleza y de la felicidad, una religión que establezca la paz y la armonía entre el cuerpo y el alma, y el cielo en la tierra.

Ahora bien, el campo cristiano se dividió entre católicos, seguidores del refinado florentino León X, y protestantes, seguidores del ingenuo y casto monje Lutero. Lo que este rechazaba era el pacto católico entre espíritu y materia, entre alma y cuerpo, por el cual los pecados del cuerpo se convertían en dinero con el que elevar templos al espíritu. De ahí que Lutero defendiera el espiritualismo contra el sensualismo: nada de indulgencias, nada de concubinas, nada de imágenes, nada de santos y nada de milagros. Lutero supuso el triunfo de la seriedad, es así el monje elegido por la Providencia, el hombre más grande de la historia alemana, siendo, además, el más alemán: unió lo místico y lo práctico, el lenguaje y la espada, la ebriedad divina y la escolástica, la ternura y la impetuosidad, el temor a Dios y el gusto por el vino, la mujer y el canto. El rasgo más importante del protestantismo fue, con todo, la defensa de la razón como intérprete de la Biblia, lo que dio lugar al establecimiento de la libertad de pensamiento, origen de la filosofía alemana. De modo que -avisa Heine-, si en Alemania se impone la censura, se está yendo directamente contra la esencia de lo alemán, y se acabará desmantelando la Universidad, sede de la libertad de pensamiento y por ende permanente fomento de la revolución por venir.

A la revolución religiosa de Lutero le siguió la revolución filosófica de Kant, cuyos antecedentes rastrea Heine con detalle. Descartes fue el iniciador de la filosofía moderna al establecer la autoconciencia como fundamento, descartando la fe, la tradición, la escolástica y el empirismo. De él arrancan tres caminos: la senda del sensualismo y el materialismo -Locke-, la senda del espiritualismo y el idealismo -Leibniz- y la senda intermedia, la de la identidad o paralelismo entre materia y espíritu o entre extensión y pensamiento-Spinoza-. El idealismo, heredero de Platón y presente en los místicos y en los pietistas, es antirrevolucionario y «no ha tenido nunca fortuna en Francia» (Heine, 2015, 80); sin embargo, «Alemania ha manifestado

8 Cf. Lukács 1937. Considero que es un error metodológico medir a Heine con el metro de Marx-Engels y de la revolución de 1848, tal como hace Lukács. Si todo lo que Marx-Engels escribieron era cierto y sus interpretaciones de la historia son las canónicas, es lógico entonces que se pueda valorar positivamente a Heine cuando se acerca a ellas, forzar lo que parece que dice para que diga algo próximo a la verdad y rechazar de plano todo lo que vaya en su contra. Es lógico, digo, que así el retrato resultante de Heine sea fragmentario, contradictorio, desilusionante. Lo que no está claro es que así salga a la luz Heine mismo. En efecto, cabe preguntase, ¿cómo quedaría el retrato de Marx-Engels realizado con la irónica medida de Heine? 
desde siempre una antipatía por el materialismo, y por eso ha sido durante siglo y medio la verdadera escena del idealismo» (Heine, 2015, 82). El materialismo, por su parte, heredero de Aristóteles y presente en los dogmáticos y ortodoxos, favorece la revolución, de ahí que «los filósofos franceses eligieron probablemente a John Locke como maestro universal. Este era el Salvador que necesitaban [los Condillac, Helvetius, Holbach, La Metrie]» (Heine, 2015, 81). Esta corriente promueve también la revolución en Inglaterra, de mano de los benthamistas, pero nunca tendrá éxito en Alemania, al revés que los saint-simonianos. Spinoza, por fin, sintetiza a Locke y a Leibniz, ni es ateo ni deísta, sino panteísta ${ }^{9}$. Al identificar mundo y Dios -aunque Heine destaca también la identificación entre Dios y humanidad-, el panteísmo hace divino al mundo, permite reivindicar el cuerpo y el goce sin negar el espíritu. No es enemigo del materialismo sino su auxiliar, al aportar la síntesis religiosa que le falta al materialismo. Ni los enciclopedistas ni Voltaire sintonizan entonces con Alemania, y Jacobi, el enemigo de Spinoza, «no fue sino un intrigante espía» (Heine, 2015, 95).

El primer filósofo que utilizó la lengua alemana fue Christian Wolf, quien, al sistematizar el abigarrado pensamiento de Leibniz, dio lugar a la polémica en torno a la Ilustración en Alemania, tanto en religión -enfrentamiento entre pietistas y protestantes o entre escolástica y racionalismo- como en filosofía, en torno al moralismo inglés, el filantropismo francés, el deísmo, la masonería y el cosmopolitismo. Es de destacar la consideración de Federico el Grande como «materialismo coronado» (Heine, 2015, 102), el cual «no tuvo mucha influencia en el espíritu alemán. Más bien ofendía y humillaba al sentimiento nacional» (Heine, 2015, 103), y de Moses Mendelssohn como quien «destruyó el catolicismo hebreo, igual que Lutero había destruido el cristiano» (Heine, 2015, 107).

Con todo, es Kant el filósofo al que Heine dedica más páginas, interviniendo así decisivamente en la polémica en torno al kantismo. Kant, con su Crítica de la razón pura, descabezó el deísmo en Alemania por lo que, considera Heine, «ningún otro escrito de Kant tiene mayor significación» (Heine, 2015, 117). Heine ya recoge la anécdota sobre la puntualidad de Kant y destaca su honestidad y la dificultad del estilo literario de sus obras mayores -que no es el de sus obras menores-. De su filosofía, destaca la distinción entre noúmeno y fenómeno, el giro copernicano ${ }^{10} \mathrm{y}$ las críticas a las pruebas ontológica, cosmológica y físico-teológica de Dios, aunque reconoce su disgusto «al ver discutir a alguien la existencia de Dios» (Heine, 2015, 123) puesto que, para él, la cuestión no es si existe Dios o no, sino cuál sea su naturaleza. De ahí que valore la crítica kantiana al deísmo, no en tanto que camino al ateísmo, sino como modo de despejar el camino al panteísmo, y que considere una burla la prueba moral de Dios establecida en la Crítica de la razón práctica, respecto a la que, por cierto, se pregunta si Kant la defendió por respeto al pueblo, por miedo a la policía o por convicción personal.

9 Heine recuerda, como antecedentes del panteísmo, a los animistas medievales alemanes Tauler, Paracelso y Böhme.

10 La versión heiniana es: «Por eso compara [Kant] con razón su filosofía con el proceder de Copérnico. (...) Antes, la razón, como el Sol, giraba en torno a los fenómenos de este mundo e intentaba iluminarlos; Kant, empero, hace que la razón, el Sol, se quede quieta, y el mundo de los fenómenos gire en torno suyo y se ilumine según que entre o no en el ámbito de este sol» (Heine, 2015,121). Santayana diría, por el contrario, que Kant fue anticopernicano puesto que, si Copérnico acertó al colocar al Sol en el centro, Kant se equivocó al colocar, no sólo gnoseológica sino también ontológicamente, al sujeto en el centro, en torno al cual gira el universo entero. 
De Fichte, Heine se centra en su Teoría de la ciencia, puesto que de su segundo periodo escribe que «nos importa poco aquí» (Heine, 2015, 147). El sistema fichteano se basa en el «tremendo error» (Heine, 2015, 141) de considerar Absoluto el Yo -con mayúsculas, no el suyo particular, confusión que está a la base de las numerosas sátiras, las del propio Heine incluidas, que Fichte tuvo que soportar- y supone la defensa del idealismo más absoluto, alejado por completo de todo escepticismo, eclecticismo o moderación. Es la contrapartida del materialismo francés. De ambos afirma Heine que «los dos me repugnan. Los puntos de vista de ambos son antipoéticos» (Heine, 2015, 142). De ahí que se centre sobretodo en la relación personal de Fichte con Kant, dando cuenta a los franceses de las cartas en las que Fichte cuenta sus avatares en Königsberg, ciertamente interesantes. También relata pormenorizadamente la acusación de ateísmo que pesó sobre Fichte mientras enseñaba en Jena y el ambiguo papel que en tal affaire tuvieron dos importantes cargos públicos, Goethe y Herder. Aunque Heine mismo rechaza el ateísmo ${ }^{11}$, no por eso deja de ver en la acusación contra Fichte una persecución política, por lo que reproduce un extenso fragmento de la interesante carta de Fichte a Reinhold donde dice ver la mano de Rusia y de Austria tras los intentos de apagar la libertad en Alemania, sostenida por los franceses ${ }^{12}$. Heine está de acuerdo con este análisis, por lo que escribe: «Sin Napoleón, nuestros filósofos, junto con sus ideas, habrían sido exterminados por la horca y la rueda» (Heine, 2015, 146).

Mientras en filosofía, con todo, se imponía el idealismo de Fichte, en literatura, con la escuela romántica formada en torno a los hermanos Schlegel, se imponía el panteísmo. Al entusiasmarse por la literatura germana precristiana reavivaron, sin saberlo, el panteísmo, que, en versión filosófica corresponde a la filosofía de la naturaleza de Schelling. Este acepta la identificación de lo ideal y lo real, de la naturaleza y el pensamiento, pero, en lugar de construir lo real a partir de lo ideal, tal como hace Fichte, Schelling explica lo ideal partiendo de lo real ${ }^{13}$. La diferencia en estilo es también clara: «la poesía es la fuerza y la debilidad del señor Schelling. Por ella se diferencia de Fichte, tanto en beneficio cuanto en perjuicio propios. Fichte es exclusivamente filósofo, y su fuerza está en la dialéctica, en el demostrar. Este es, en cambio, el lado débil del señor Schelling, que vive más en intuiciones, no se siente a gusto en las frías alturas de la lógica, se precipita gustoso a los floridos valles del simbolismo, y cuya fuerza filosófica es la construcción» (Heine, 2015, 149). No ha de extrañar por tanto que sea el Schelling de la filosofía de la naturaleza el que le sirva a Heine de marco filosófico para su impulso poético. El ciclo completo de la filosofía alemana queda resumido así: «Los alemanes, luego de despreciar el materialismo de Locke, llevar al extremo el idealismo de Leibniz y ver que también era estéril, llegaron finalmente

11 «Nosotros, que creemos en un Dios real que se revela a nuestros sentidos en la extensión infinita y a nuestro espíritu en el pensamiento infinito, nosotros, que veneramos a un Dios visible en la naturaleza y percibimos su invisible voz en nuestra propia alma, nos sentimos molestamente heridos por las violentas palabras con que Fichte declara que nuestro Dios es una alucinación digna de ironías» (Heine, 2015, 141).

12 Cf. Heine, 2015, 142-144.

13 Así suenan las formulaciones de Heine, a las que habría que añadir una matización importante, dado que Fichte no construye exactamente lo real sino la interpretación de lo real a partir de lo ideal, y Schelling, cuando habla de lo real, ya lo entiende interpretado idealmente. Con todo, es un matiz que en el idealismo se suele olvidar con demasiada facilidad. Precisamente fue Santayana el filósofo que estuvo siempre atento a ese matiz: él aceptó el idealismo gnoseológico, pero advirtió de su inadvertida conversión en idealismo ontológico, para la que, como se verá infra, acuñó el término egotismo. 
al tercer hijo de Descartes, a Spinoza. La filosofía cerraba de nuevo un gran ciclo, y puede decirse que se trataba del mismo círculo descrito también dos mil años antes en Grecia» (Heine, 2015, 150). Con la concepción de Dios de Schelling se cierra el círculo: una divinidad donde se da la identidad absoluta de la naturaleza y el pensamiento, de la materia y el espíritu, la identidad absoluta y la totalidad absoluta. Hasta aquí sigue Heine a Schelling, pero ya no puede seguirle cuando quiere intuir el Absoluto mismo y menos aún cuando se acerca al absolutismo político y al jesuitismo, es decir, cuando «es apóstata de sí mismo» (Heine, 2015, 153).

Las famosas páginas finales las dedica Heine a refutar la tesis de los amantes de la libertad, para quienes la filosofía sume a la juventud en abstracciones y la hace inútil para la vida práctica. Heine considera, por el contrario, que la revolución por venir llevará a la práctica la crítica sin compasión al pasado de Kant, el fanatismo de la voluntad de Fichte y la ferocidad primigenia natural de Schelling. A la vez, recomienda a los franceses, acaso irónicamente, que ni aviven el fuego de la revolución, ni intenten apagarlo, que ni siquiera aplaudan, pero, eso sí, que no se desarmen, por si acaso, dado que la mitad de Alemania no quiere a Francia.

\section{Santayana sobre la filosofía alemana}

Emulando al autor de los enigmáticos Dissoì lógoi, es fácil enfrentar, casi punto por punto, las tesis heineanas con las tesis enfrentadas de Santayana. Si Heine alaba la fusión de filosofía y religión en Alemania, a Santayana le desagrada tal mezcolanza ${ }^{14}$; si la Universidad es el lugar de la filosofía y fermento de la revolución para Heine, Santayana responde que ahí habitan profesores de filosofía no filósofos, y que sus experiencias en Harvard le indican que, una vez completada la revolución, la Universidad, ya profesionalizada, sirve al industrialismo; si el protestantismo va unido a la libertad de pensamiento -la misma narración de Heine muestra que esa vinculación es más un deseo que una realidad-, Santayana objeta que los protestantes no saben qué hacer con la libertad conquistada ${ }^{15}$; si Kant es el filósofo que hace superior a la filosofía alemana, incluso respecto a la griega, Santayana considera que Kant no ocupa ningún lugar relevante en la historia de la filosofía ${ }^{16}$ y que, si se comparan el idealismo alemán y el idealismo griego, este gana con ventaja ${ }^{17}$; si el materialismo no le resulta a Heine ni filosófico ni poético, Santayana responde dedicándole un bello ensayo al filósofo-poeta Lucrecio en su libro Tres poetas filósofos. Lucrecio, Dante,

14 En carta a W. James del dieciocho de diciembre de 1887 , le escribe sobre la filosofía que está estudiando en Alemania: «La gran ruina de la filosofía es el afán teológico que empuja al hombre hacia verdades finales e intolerantes como su salvación».

15 El protestantismo «es la autoconciencia de un espíritu en proceso de incubación, orgulloso de sus potencialidades, reacio a definiciones y exteriorizaciones de cualquier tipo, porque no puede discernir nada fijo o final» (Santayana, 2015, 67).

16 «Si se trazara una línea recta de progreso a través del laberinto completo de la filosofía, Kant no estaría en esa línea. Su pensamiento es esencialmente excéntrico y sofisticado, se basa enteramente en dos disparates heredados que una filosofía verdaderamente progresiva tendría que evitar desde el comienzo, dejando a Kant a un lado y sorteando su filosofía como se haría con Escila y Caribdis» (Santayana, 1913, 61).

17 Cf. Santayana 2013a, un excelente diálogo en el limbo donde Santayana pone en boca de Sócrates una humorística presentación de Fichte, Hegel y Schopenhauer. 
Goethe y etiquetándose a sí mismo como materialista ${ }^{18}$; finalmente, a la ingenua tesis de que el alemán es el idioma de la filosofía -boutade tan repetida y, se supone, a veces, tan creída-, Santayana simplemente no respondería, del mismo modo que, alabando también a Spinoza, no se pondría de acuerdo con Heine en su interpretación.

Se explica así que El egotismo en la filosofía alemana esté plagado de referencias contrarias a Sobre la historia de la religión y la filosofía en Alemania. Por mor de la brevedad, recogeré únicamente las más relevantes. Ya en el Prefacio, Santayana confiesa: «Durante más de veinte años, mientras enseñaba filosofía en la Universidad de Harvard, tuve continuamente ocasión de leer y discutir la metafísica alemana. Desde el comienzo revestía a mis ojos una forma más bien sospechosa. Bajo sus oscuros y fluctuantes principios, sentía que algo siniestro se incubaba, algo a la vez hueco y agresivo. Me parecía un método forzado de especulación, que producía mayor confusión de la que había, y calculado principalmente para permitir a los materialistas prácticos llamarse a sí mismos idealistas y a los racionalistas seguir siendo teólogos» (Santayana, 2014, 45). De modo que para conceptualizar la exaltación del $\mathrm{Yo}^{19}$ como Absoluto, Santayana utiliza el término egotismo, entendido como una forma extrema de subjetivismo cuya «convicción fundamental es que no hay cosas existentes, excepto las imaginadas: Dios, igual que la materia, queda agotado por el pensamiento de Él y es del todo inherente a este pensamiento» (Santayana, 2014, 50). Tal como Heine reconocía en Schelling, el idealismo convierte lo real en ideal, algo que a Santayana le parece muy humano, incluso animal, pero que olvida «el sentido platónico y poético en el que el ideal es una cosa mejor que el hecho» (Santayana, 2014, 52). De ahí el éxito popular del idealismo, basado, a nivel filosófico en una serie de ambigüedades: «No se puede sostener que el mundo natural es producto de la mente humana sin cambiar el sentido de la palabra mente y de la palabra humana. No se puede negar la existencia de una substancia sin convertir en substancia aquello que ocupe su lugar. No se puede uno identificar con Dios sin afirmar y negar a la vez la existencia de Dios y de uno mismo» (Santayana, 2014, 53). La misma postura de Heine queda descrita así por el desasido Santayana: «así como en el panteísmo Dios es puesto, sobre bases naturalistas, como una fuerza cósmica, en la filosofía alemana la piedad bíblica de los protestantes primitivos es secularizada y convertida en fervor patriótico y social» (Santayana, 2014, 58).

Bajo estas afirmaciones late el presupuesto materialista de la filosofía de Santayana, desde el cual se puede denunciar el paso en falso que se da cuando una noción epistemológica se convierte imperceptiblemente en una arriesgada afirmación ontológica. El pensamiento moderno consideró al sujeto como dador de sentido, al descubrir su papel como único y obligado camino de acceso al mundo entorno: puesto que del mundo sólo tenemos ideas y éstas se encuentran en el pensamiento, el yo se convierte en lo más indudable y, por ende, en lo más real. De ahí se sigue, coherentemente, la llamativa afirmación de que el sujeto crea el mundo conocido, puesto que, para ser conocido, el mundo necesita un sujeto que lo organice espacio-temporalmente y lo dote de distintas relaciones, la causalidad entre ellas. El paso en falso, o falacia, se da cuando

18 «En filosofía natural soy un decidido materialista -aparentemente el único vivo» (Santayana, 2011, 11).

19 En el capítulo «¿Qué es el ego?» muestra Santayana que el Yo no puede ser ni una persona particular, ni su yo cuando está pensando, ni la gramática común de todo ser pensante, ni Dios y su Logos. El Yo carecería de tiempo y de espacio, sería «una unidad pura, un inefable e intenso centro del que no irradia nada» (Santayana, 2014. 193); carecería, en definitiva, de experiencia. 
se olvida el adjetivo conocido, y se escribe, sin más, que el sujeto crea el mundo, dando por hecho que mundo y mundo conocido son sinónimos. De una afirmación tautológica, que para que el mundo sea conocido ha de haber algo que lo conozca, se pasa a un absurdo: que para que el mundo exista ha de haber un sujeto que exista ${ }^{20}$.

Leibniz ocupa también, según Santayana, el primer lugar dentro de la filosofía alemana, en especial su Monadología, respecto a la cual Kant potenció su subjetivismo. Las múltiples mónadas leibnizianas se convirtieron en una sola, y lo hicieron así porque los idealistas toman la cosa por la idea de la cosa en el pensamiento y concluyen que las cosas existen sólo como percibidas, y que el mundo es creado al quererlo y al pensarlo. Kant mismo no llegó a pensar así, pero, con su distinción entre noúmeno y fenómeno, puso las semillas. Heine y Santayana están de acuerdo en considerar que las dos primeras Críticas kantianas no encajan entre sí, Heine habla de apostasía y Santayana de falacia: «por esto [Kant] se apresuró a adoptar un principio correctivo de reconstrucción, no menos falaz, a saber, que la conciencia nos ordena admitir como reales algunas cosas acerca de las cuales nada conoce la razón ni la experiencia» (Santayana, 2014, 84). La filosofía de Fichte es calificada por Santayana como trascendentalismo perfeccionado; igual que Heine decía de él que producía lo real a partir de lo ideal, Santayana considera que, bajo el idealismo de Fichte, se esconde la adoración del mundo, de la nación (alemana) y de la naturaleza en su constante desenvolvimiento, por eso escribe que «no resulta paradójico que los idealistas se encuentren tan a sus anchas entre las cosas materiales. Según ellos, estas cosas materiales son hijas de su espíritu» (Santayana, 2014, 92); mientras que es el materialismo -Santayana mismo- el sistema que, tras reconocer la base material de lo espiritual, se interesa por todo lo que procura eludir la presión de la naturaleza, intentando incluso retirarse al mundo de la mente en busca de paz y ocio. El idealismo, sin embargo, busca la guerra, la lucha, el trabajo, la puesta en práctica constante de su voluntad.

Santayana continúa su disección de Fichte analizando el ingenuo, intenso y peligroso nacionalismo fichteano, algo que Heine deja a un lado; además, Santayana deja lamentablemente a Schelling fuera de su recorrido, por lo que no se pueden extraer de El egotismo en la filosofía alemana respuestas directas a los planteamientos heineanos. Dado que el recorrido santayaniano continúa con Stirner, Schopenhauer y Nietzsche, autores no tratados por Heine, nuestro análisis ha por tanto de acabar aquí.

A modo de no-conclusión, puesto que al comienzo prometí sólo un repaso informativo -e imparcial, en la medida en que esto sea posible- a dos autores poco visibles, me gustaría recoger dos opiniones informadas pero críticas respecto al planteamiento de Santayana. Eugenio Moya, por ejemplo, en la reseña de El egotismo en la filosofía alemana, alude al riesgo que corre la filosofía de Santayana: al cuestionar el sujeto se puede cuestionar también la razón y abrir la puerta al irracionalismo ${ }^{21}$. Y Ramón del Castillo, al comparar la postura de Santayana con la de Dewey, considera al naturalismo santayaniano incapaz de salir de sí y de congeniar con el mundo, algo que sí logra el naturalismo deweyano ${ }^{22}$.

20 Se puede pensar que es a este engaño al que Santayana se refiere en su carta a Antonio Marichalar del 14 de junio de 1933 cuando, en castellano, le escribe: «Cruz y Raya me interesa y me instruye mucho; solamente me extraña un poco que los alemanes hayan podido engañar con tanta facilidad a los filósofos españoles» (Santayana, 2013b, 127).

21 Cf. Moya 2013, 149.

22 Cf. Del Castillo 2011, 164. 


\section{Referencias}

Aub, M. (2000), Heine, introducción de Mercedes Figueras, Fundación Max Aub, Valencia. Beltrán, J. (22008), Celebrar el mundo. Introducción al pensar nómada de George Santayana, Universidad de Valencia, Valencia.

Del Castillo, Ramón (2011). «Espectros del idealismo: Santayana y Dewey», en Santayana: un pensador universal, José Beltrán, Manuel Garrido y Sergio Sevilla, eds., Universidad de Valencia, Valencia, pp. 139-165.

Duque, F. (1999), La Restauración. La escuela hegeliana y sus adversarios, Akal, Madrid.

Heine, H. (1967), «Confesiones», en Heinrich Heine, Obras [en prosa], introducción y traducción de Manuel Sacristán, Vergara, Barcelona, pp. 981-1046.

Heine, H. (2008), Sobre la historia de la religión y la filosofía en Alemania, edición de Juan Carlos Velasco, Alianza Editorial, Madrid.

Heine, H. (2015), Sobre la historia de la religión y la filosofía en Alemania. La escuela romántica, edición e introducción de Manuel Garrido, traducción y estudio crítico de Manuel Sacristán, Tecnos, Madrid.

Lukács, G., (1937), «Heine como poeta nacional», en Georg Lukács, Realistas alemanes del siglo XIX, traducción de Jacobo Muñoz, Grijalbo, Barcelona, 1970, pp. 95-157.

Moreno, D. (2007), Santayana filósofo. La filosofía como forma de vida, Trotta, Madrid.

Moreno, D. (2014), «El egotismo como paso en falso de la filosofía», en George Santayana, El egotismo en la filosofía alemana, Biblioteca Nueva, Madrid, pp. 11-26.

Moya, E. (2013), «El egotismo como patología moderna.» Limbo. Boletín internacional de estudios sobre Santayana $\mathrm{n}^{\circ} 33$ (2013), pp. 133-152.

Sacristán, M. (1964), «Heine, la consciencia vencida», en Heinrich Heine, Obras [en prosa], traducción, prólogo y notas de Manuel Sacristán, Editorial Vergara, Barcelona, pp. 7-98.

Santayana, G. (1913), Winds of Doctrine, Scribner's, Nueva York.

Santayana, G. (2011), Escepticismo y fe animal, traducción de Ángel M. Faerna, Antonio Machado Libros, Madrid.

Santayana, G. (2013a), «Los dos idealismos. Un diálogo en el limbo», traducción de Daniel Moreno, Revista de Occidente, no 391 (2013), pp. 39-62.

Santayana, G. (2013b), «Dieciséis cartas inéditas de George Santayana a Antonio Marichalar», Limbo. Boletín internacional de estudios sobre Santayana, no 33, (2013), pp. 109-132.

Santayana, G. (2014), El egotismo en la filosofía alemana, edición de Daniel Moreno, Biblioteca Nueva, Madrid.

Santayana, G. (2015), «Protestantismo», en George Santayana, Pequeños ensayos sobre religión, traducción y presentación de José Beltrán y Daniel Moreno, Trotta, Madrid, pp. 67-70.

Savater, F. (2012), Acerca de Santayana, Publicaciones Universidad de Valencia, Valencia.

Velasco, J. C. (2008), «Heine y los años salvajes de la filosofía», en Heinrich Heine, Sobre la historia de la religión y la filosofía en Alemania, edición de Juan Carlos Velasco, Alianza Editorial, Madrid, pp. 7-45. 